\title{
Prosthodontic Rehabilitation of an Ectodermal Dysplasia Patient with Artificial Saliva Reservoir in Complete Denture
}

\author{
Nitai Debnath, Renu Gupta, A Shakthi Devi, A Meenakshi, K Ramkumar
}

\begin{abstract}
Ectodermal dysplasia is an inherited disorder accompanied with hypoplasia or dysplasia of the tissues derived from ectodermal origin. Uncommonly, xerostomia can be seen in ectodermal dysplasia. Xerostomia is an unhealthy, uncomfortable, unhygienic condition of the oral cavity, presents with symptoms like soreness, constant burning sensation, halitosis, altered taste, speech and prone for fungal infection. This article presents a case report of an ectodermal dysplasia patient with xerostomia, successfully treated with saliva reservoir denture. Palatal hollow space in upper denture and mandibular hollow denture is used as reservoir space for carboxymethyl cellulose containing artificial saliva, to rehabilitate the complete edentulous mouth with xerostomia.
\end{abstract}

Keywords: Ectodermal dysplasia, Xerostomia, Saliva reservoir, Artificial saliva, Carboxymethyl cellulose.

How to cite this article: Debnath N, Gupta R, Devi AS, Meenakshi A, Ramkumar K. Prosthodontic Rehabilitation of an Ectodermal Dysplasia Patient with Artificial Saliva Reservoir in Complete Denture. Int J Prosthodont Restor Dent 2013;3(1): 37-41.

\section{Source of support: Nil}

Conflict of interest: None

\section{INTRODUCTION}

Ectodermal dysplasia is an inherited hereditary disorder characterized by aplasia or dysplasia of tissues of ectodermal origin such as teeth, hair, nail and sweat glands. ${ }^{1-3}$ It is classified as an X-linked recessive hypohidrotic form and an autosomal dominant hidrotic form. The hidrotic form is associated with the presence of sweat glands, but the other features are same as with hipohydrotic form. ${ }^{4}$

Xerostomia presents with dry oral mucosa and decrease saliva flow rate. Often, one-third of the patients with ectodermal dysplasia have severe xerostomia with decrease in both unstimulated $(<0.1 \mathrm{ml} / \mathrm{min})$ and stimulated $(<0.7 \mathrm{ml} / \mathrm{min})$ saliva flow rate. ${ }^{5}$ Patient with xerostomia usually complaints of oral soreness, burning oral mucosa, halitosis, altered taste sensation and speech. ${ }^{6,7}$ The aim of prosthodontic rehabilitation is not only to establish esthetics and masticatory efficiency, but also to restore other functional requirements. This article describes a case of ectodermal dysplasia, successfully treated with artificial saliva reservoir in both upper and lower complete dentures.

\section{CASE REPORT}

A 21-year-old male patient presented with a chief complaint of dryness of his mouth and difficulty to chew food. There was no relevant medical history. Dental history revealed that there were few erupted permanent teeth in the mouth which were later extracted due to dental caries and periodontal disease. The patient stated history of intolerance to heat. Extraoral examination revealed dry scaly skin, depressed nose, frontal bone bossing, under developed right and left pinna, thin sparse hair and eyebrows (Fig. 1). Intraoral examination revealed that the patient is completely edentulous with dry oral mucosa. None of his family members had such type of problems. With the above-stated findings, a diagnosis of hypohidrotic ectodermal dysplasia was given.

To find out the reason for dry oral mucosa, the saliva flow rate test was done. Citric acid droplets (lemon extract) in the mouth was used as a stimulus to increase the saliva secretion. Patient was asked to spit into a beaker in an interval of 5, 10 and 15 minutes and the amount of saliva secreted per minute was measured. The unstimulated saliva flow rate was measured in the similar manner without any external stimuli. The procedure was performed for 3 consecutive days. The mean unstimulated saliva flow rate was found to be 0.025 $\mathrm{ml} / \mathrm{min}$ and stimulated saliva flow rate was $0.3 \mathrm{ml} / \mathrm{min}$ which was below the normal flow rate. This test confirmed that the patient was suffering from xerostomia. Therefore, upper

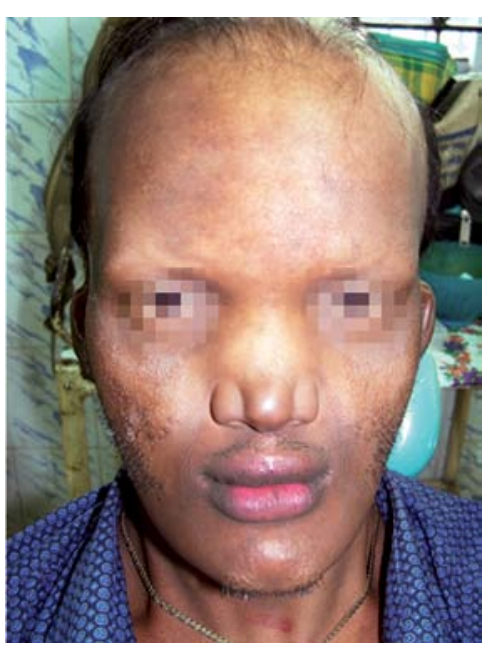

Fig. 1: Preoperative photograph of the patient 
palatal reservoir and lower hollow denture reservoir space for artificial saliva was planned for the patient.

The treatment procedure was as follows:

1. Primary impression of both the arches was taken with impression compound and for final impression light body polyvinyl siloxane impression material was used instead of zinc oxide eugenol impression paste, as eugenol can aggravate the burning sensation of mouth.

2. Conventional jaw relation and wax trying procedure was done.

\section{Fabrication of Maxillary Palatal Saliva Reservoir}

A $0.45 \mathrm{~mm}$ thick casting wax sheet was adapted on the palatal surface of the maxillary refractory cast, keeping it 3 to $4 \mathrm{~mm}$ away from posterior palatal seal area and 1 to $2 \mathrm{~mm}$ away from the crest of the ridge. All around the border of the wax sheet, four vertical walls of 2 to $3 \mathrm{~mm}$ height was made in the palatal vault area, using lingual bar wax strip. Vertical walls were made to create a bounded hollow space for the palatal reservoir. Four castable plastic sphere OT caps (Rhein 83 Attachment) of $2 \mathrm{~mm}$ diameter were placed parallel to each other on the center of each vertical wall (Fig. 2A). Thereafter, the denture mesh wax was adapted around the outer border of vertical walls (Fig. 2B) and casting was done with $\mathrm{Co}-\mathrm{Cr}$ alloy. Sandblasting and polishing of the metal framework was done.

Flasking of the wax try-in denture was done in a conventional manner. After dewaxing procedure, the metallic framework was fixed on the master cast embedded in flask with cyanoacrylate cement in its respective position and the reservoir space was closed with lab putty material (Unisil Putty, Delta). Denture was processed with polymethyl methacrylate resin (DPI, India) using compression mold technique. Figure $2 \mathrm{C}$ shows the metallic framework partially embedded into the acralized denture. Two white (standard) and two pink (soft) OT caps of Rhein 83 attachment of $2 \mathrm{~mm}$ diameter each was selected and placed over the casted metallic sphere of the upper denture (Figs 2D and E). To make an escape path for artificial saliva, a cellophane sheet was placed on the posterior border of the reservoir, the reservoir space closed with Unisil putty (Delta, India) and the overlying lid was fabricated with autopolymerizing resin (DPI, India) (Fig. 2F). This resulted in a removable lid with OT caps embedded in it. For injecting artificial saliva into the reservoir space, an injecting hole of $0.5 \mathrm{~mm}$ diameter was made on the intaglio surface of the metallic framework with a round carbide bur. After injecting artificial saliva into the palatal reservoir space, it oozes slowly out of the reservoir space by posterior border of lid and keeps the oral cavity moist.

\section{Fabrication of Mandibular Denture with Artificial Saliva Reservoir}

A permanent record base was fabricated with polymethyl methacrylate resin (DPI, India) on the duplicated mandibular cast. Three ' $v$ '-shaped notches were made at three corners of the permanent record base (Fig. 3A). Two identical metal flasks were used for processing purpose. After dewaxing of
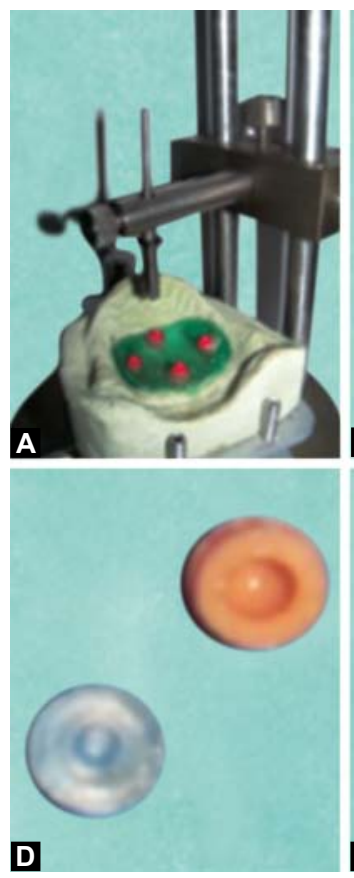
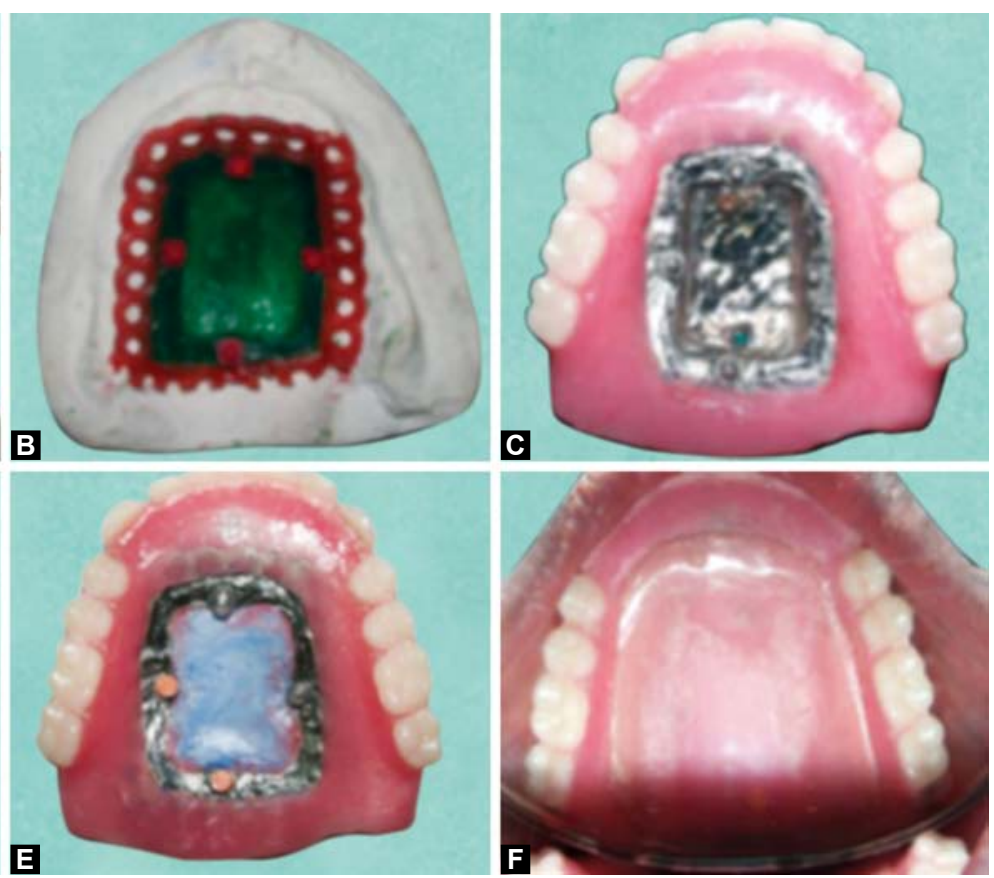

Figs 2A to F: Laboratory steps for maxillary denture with saliva reservoir: (A) castable plastic sphere placed on the cast with parallelometer (B) mesh wax adapted on cast, (C) denture with metal frame work, (D) silicone O-ring, (E) O-ring over the metal sphere, (F) maxillary denture with attached removable lid 
the wax try-in denture, the permanent record base was placed on the cast embedded to the lid (of the first flask) and trial closure was done with modeling clay material (Jingjing, China) (Fig. 3B). After trial closure, the lid of the first flask was replaced by the lid of second identical flask and a second trial closure was done with dental stone (Kalastone, Kalabhai, India). After setting of the dental stone, the flask was opened and the modeling clay was removed from the flask with hot water spray and the denture was processed with heat-cured resin (DPI, India). Thus, the lower denture was fabricated in two parts, the first part being the permanent record base and the second part containing artificial teeth. In order to obtain a hollow space in the denture, excess acrylic resin from the intaglio surface of the second part of denture was trimmed away leaving the borders intact. With the help of three ' $v$ '-shaped notches, two parts of the lower denture were easily oriented and fused with autopolymerizing resin (DPI, India) at the borders. To inject artificial saliva into the hollow space, two injecting holes were made on the both distolingual aspect of lower denture, till the depth of hollow space. Hollow plastic cap of a $2 \mathrm{ml}$ disposable syringe and the hub of that respective needle, which fits snugly with each other, was used to fabricate a snugly fitted removable lid for the injecting hole (Fig. 3C). First hollow plastic cap at the opened end was cut into $2 \mathrm{~mm}$ in length and attached into the injecting hole of the denture with autopolymerizing resin on both side (Fig. 3D). Thereafter, petroleum jelly applied around the injecting hole and the hub of the needle was snugly fitted into the hollow plastic cap. Autopolymerizing resin with a thickness of $1 \mathrm{~mm}$ applied around the injecting hole in dough stage. After polymerization, this resulted in a removable lid with hub of the needle embedded in it (Fig. 3E). Because of the presence of hollow air space in lower denture, it was floating in water (Fig. 3F). A releasing hole of $0.2 \mathrm{~mm}$ diameter made in the anterior lingual part of the denture below the level of injecting holes, to allow the artificial saliva to flow out of reservoir space and keep the mouth moist.

Carboxymethyl cellulose (CMC)-containing artificial saliva (Wet mouth, ICPA) (Fig. 4) was used to fill the reservoir space. Procedure of injecting artificial saliva into the reservoir space through the injecting holes and regular cleaning methods of the reservoir space were demonstrated to the patient. Third month review showed an increase in comfort during chewing and reduction in burning sensation for the patient (Fig. 5).

\section{DISCUSSION}

Ectodermal dysplasia with xerostomia is a challenge for the clinician to satisfy the patient with conventional denture due to constant burning sensation of oral mucosa with or without denture. The treatment of xerostomia depends on the etiology, severity and associated conditions. ${ }^{8}$ Different treatment options for xerostomia are medication, mastication of sugar-free chewing gum, hydration, acupuncture and prosthesis with artificial saliva reservoir.

Xerostomia due to salivary gland hypofunction can be treated with hydration therapy, mastication of sugar-free
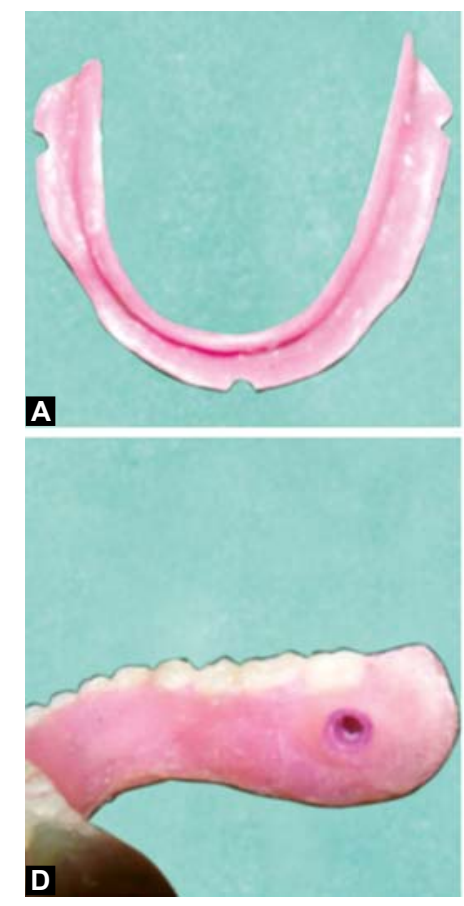
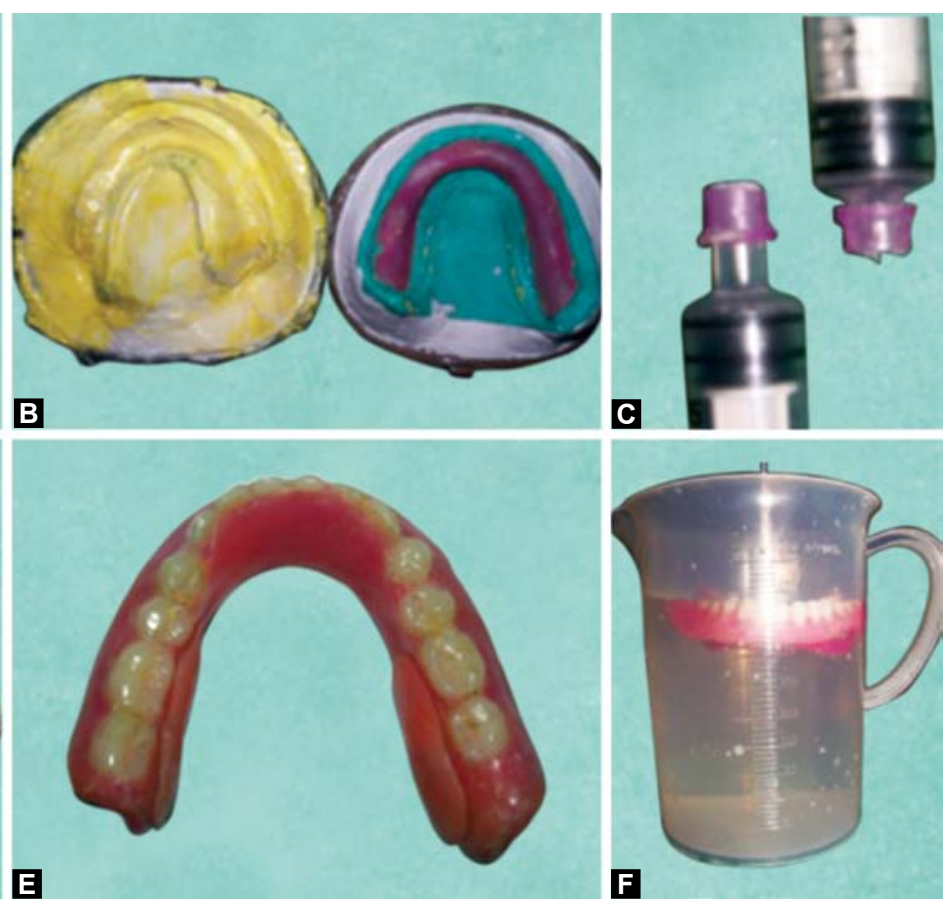

Figs 3A to F: Laboratory steps for mandibular denture with saliva reservoir: (A) permanent record base, (B) trial closure with modeling clay, $(C)$ hollow plastic caps cut from the needle, (D) hollow plastic cap fixed to the denture with autopolymerizing resin, (E) denture with attached removable lid, $(F)$ hollow denture floating in water 


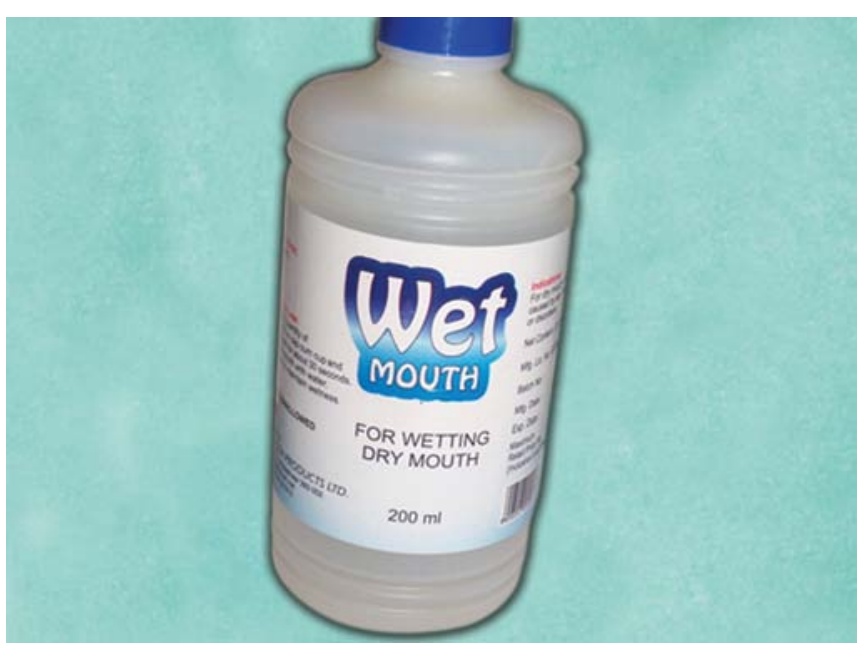

Fig. 4: Artificial saliva (Wet mouth, ICPA)

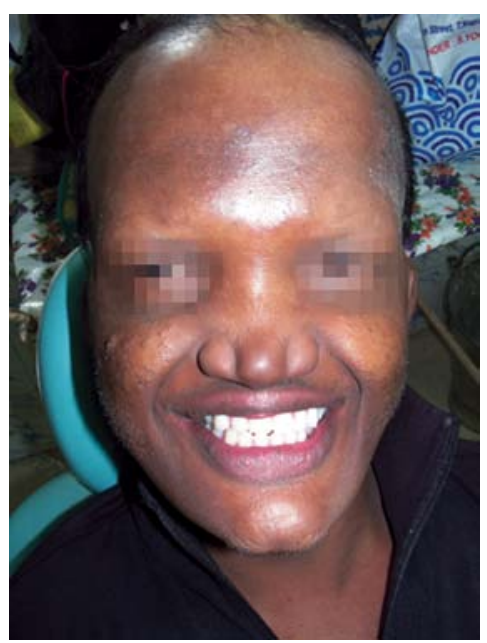

Fig. 5: Postoperative photograph of the patient

chewing gum or lozenges and with cholinergic drugs such as pilocarpine hydrochloride and cevimiline hydrochloride. ${ }^{9}$ Xerostomia as a side effect of drugs can be treated with reduction in dosage or alternative drug therapy. According to Blom and Lundeberg, acupuncture therapy improves the saliva flow rate in patient suffering from xerostomia after radiation therapy. ${ }^{10}$ Epstein et al noticed that oral balance gel reduces the burning sensation and improves swallowing and masticatory efficiency in patient with xerostomia following radiation therapy. ${ }^{11}$

The most common treatment option for xerostomia in prosthetic dentistry is the use of soft liners and artificial saliva reservoir within the prosthesis. Soft denture liners can reduce the occurrence of sore spots on the ridge. Denture with artificial saliva reservoir is one of the recommended methods for treating edentulous patients with severe xerostomia. $^{12-15}$

Vissink used maxillary palatal reservoir and mandibular reservoir denture with bilateral block of acrylic resin posterior teeth that slides into a metal track of lower denture. According to the author ease of access, cleaning and maintenance of reservoir space are the advantage of this design. The drawbacks of this design were complicated laboratory procedure, encroachment of tongue space and it requires adequate inter ridge distance. ${ }^{15}$

Mendoza and Tomlinson ${ }^{12}$ used split mandibular denture as a reservoir space for artificial saliva. Though it eliminates the encroachment of tongue space, the amount of artificial saliva in the reservoir space was less. Repair and relining of such dentures are difficult. ${ }^{12}$

Murtuza et $\mathrm{l}^{13}$ used hollow mandibular reservoir denture with stainless steel press button attachments. According to the author, the advantages of this design are easy maintenance and cleaning of reservoir space and simplified laboratory procedure.

Agarwal et $\mathrm{al}^{16}$ incorporated palatal reservoir with overlying acrylic lid containing stainless steel attachment in maxillary cast partial denture as an alternative to mandibular split denture in retained natural mandibular dentition. The encroachment into tongue space in the palatal area is the drawback of this design.

In this case report, the patient had adequate interarch space; therefore, mandibular hollow denture with reservoir space and maxillary palatal reservoir was planned.

In the laboratory procedure of mandibular hollow denture fabrication, modeling clay was used in the initial trial packing step. The reason is modeling clay flows better under pressure and is easy to remove from the flask with hot water spray. In maxillary denture fabrication, four castable sphere and OT cap of Rhein 83 attachment were used to make the overlying lid removable type. This helps in easy placement and removal of the lid and helps in easy cleaning of the reservoir space.

Studies have shown that because of the absence of thickening agent, the use of water to moisten and lubricate the oral mucosa is less effective than artificial saliva. ${ }^{17,18}$ Though mucin-containing artificial saliva has shown better wettability of oral tissues than CMC-containing artificial saliva, ${ }^{18}$ because of its porcine and bovine origin, mucincontained artificial saliva was not used in this patient. Upon review after 3 months, the patient reported with decreased burning sensation in the mouth with improved comfort and confidence.

The advantage of this design includes simplified, economical and less time-consuming laboratorial procedure. It provides easy access to clean the reservoir space and opportunity to the clinician to replace the attachment if requires in future. Clogging of food particles around the loading or draining hole of the reservoir space is also minimal. 
Metallic base used in maxillary denture increases the weight of the prosthesis and could adversely affect the retention and relining of the denture. The extra bulk of the prosthesis and encroachment of tongue space could adversely affect the speech and comfort of the patient.

Further improvement of the design may be needed to provide better patient acceptance, comfort and hygiene status.

\section{CONCLUSION}

Ectodermal dysplasia with xerostomia is an uncommon congenital disorder. Dentists are the first-line health care provider to treat such patients with artificial saliva reservoir with prosthesis. A thorough knowledge and understanding about different designs of saliva reservoir with prosthesis and the merits and demerits of each design is essential to meet the patient's high demand.

\section{REFERENCES}

1. Shigli A, Reddy RP, Hugar SM, Deshpande D. Hypohidrotic ectodermal dysplasia: a unique approach to esthetic and prosthetic management: a case report. J Indian Soc Pedod Prev Dent 2005 Mar;23(1):31-34.

2. Pigno MA, Blackman RB, Cronin RJ Jr, Cavazos E. Prosthodontics management of ectodermal dysplasia: a review of the literature. J Prosthet Dent 1996 Nov;76(5):541-545.

3. Tarjan I, Gabris K, Rozsa N. Early prosthetic treatment of patients with ectodermal dysplasia: a clinical report. J Prosthet Dent 2005 May;93(5):419-424.

4. Deshpande SN, Kumar V. Ectodermal dysplasia-Maxillary and mandibular alveolar reconstruction with dental rehabilitation: a case report and review of the literature. Indian J Plast Surg 2010 Jan;43(1):92-96.

5. Walsh LJ. Dry mouth: a clinical problem for children and young adults. Int Dent SA 2007;9(5):48-58.

6. Locker D. Subjective reports of oral dryness in an older adult population. Community Dent Oral Epidemiol 1993 Jun;21(3):165-168.

7. Greenspan D. Xerostomia: diagnosis and management. Oncology (Williston Park) 1996 Mar;10(3 Suppl):7-11.

8. Turner M, Jahangiri L, Ship JA. Hyposalivation, xerostomia and the complete denture: a systemic review. J Am Dent Assoc $2008 \mathrm{Feb} ; 139(2): 146-150$.

9. Cassolato SF, Turnbull RS. Xerostomia: clinical aspects and treatment. Gerodontology 2003 Dec;20(2):64-77.

10. Blom M, Lundeberg T. Long-term follow-up of patients treated with acupuncture for xerostomia and the influence of additional treatment. Oral Dis 2000 Jan;6(1):15-24.

11. Epstein JB, Emerton S, Le ND, Stevenson-Moore P. A doubleblind crossover trial of Oral Balance gel and Biotene toothpaste versus placebo in patients with xerostomia following radiation therapy. Oral Oncol 1999 Mar;35(2):132-137.

12. Mendoza AR, Tomlinson MJ. The split denture: a new technique for artificial saliva reservoirs in mandibular dentures. Aust Dent J 2003 Sep;48:(3):190-194.

13. Burhanpurwala MA, Magar SK, Bhandari AJ. Management of an edentulous patient having xerostomia with artificial saliva reservoir denture. J Indian Prosthodont Soc 2009;9(2):92-95.

14. Toljanic JA, Zucuskie TG. Use of a palatal reservoir in denture patients with xerostomia. J Prosthet Dent 1984 Oct;52(4):540544.

15. Vissink A Huisman MC, Gravenmade EJ. Construction of an artificial saliva reservoir in an existing denture. J Prosthet Dent $1986 \mathrm{Jul} ; 56(1): 70-74$

16. Agrawal KK, Singh SV, Rashmikant US, Singh RD, Chand P. Prosthodontic rehabilitation in Sjogren's syndrome with a simplified palatal reservoir: Two year follow-up. J Indian Prosthodont Soc 2010 Dec;10(4):249-252.

17. van der Reijden WA, Vissink A, Veerman EC, Amerongen AV. Treatment of oral dryness related complaints (xerostomia) in Sjögren's syndrome. Ann Rheum Dis 1999 Aug;58(8):465-474.

18. Sharma N, Chitre V. An in vitro comparative study of wettability of four commercially available saliva substitutes and distilled water on heat-polymerized acrylic resin. J Indian Prosthodont Soc 2008;8(1):30-35.

\section{ABOUT THE AUTHORS}

\section{Nitai Debnath}

Senior Lecturer, Department of Prosthetic Dentistry, College of Dental Science and Hospital, Indore, Madhya Pradesh, India

Correspondence Address: Quater No.1/B1, College of Dental Science and Hospital, F-12, Jhoomer Ghat, Rau, Indore-453331, Madhya Pradesh, India, e-mail: dr.nitai08@gmail.com

\section{Renu Gupta}

Department of Periodontics, Nair Hospital and Dental College Mumbai, Maharashtra, India

\section{A Shakthi Devi}

Senior Lecturer, Department of Prosthetic Dentistry, Ragas Dental College and Hospital, Chennai, Tamil Nadu, India

\section{A Meenakshi}

Professor, Department of Prosthetic Dentistry, Tamilnadu Government Dental College and Hospital, Chennai, Tamil Nadu, India

\section{K Ramkumar}

Assistant Professor, Department of Prosthetic Dentistry, Tamilnadu Government Dental College and Hospital, Chennai, Tamil Nadu, India 